\title{
Temperature-Dependence of Predator-Prey Dynamics in Interactions Between the Predatory Fungus Lecophagus sp. and Its Prey $L$. inermis Rotifers
}

\author{
Edyta Fiałkowska $^{1}$ (D) Agnieszka Pajdak-Stós ${ }^{1}$
}

Received: 2 June 2017 / Accepted: 22 August 2017 /Published online: 30 September 2017

(C) The Author(s) 2017. This article is an open access publication

\begin{abstract}
Temperature is considered an important factor that influences the bottom-up and top-down control in water habitats. We examined the influence of temperature on specific predatory-prey dynamics in the following two-level trophic system: the predatory fungus Lecophagus sp. and its prey Lecane inermis rotifers, both of which originated from activated sludge obtained from a wastewater treatment plant (WWTP). The experiments investigating the ability of conidia to trap rotifers and the growth of fungal mycelium were performed in a temperature range that is similar to that in WWTPs in temperate climate. At $20^{\circ} \mathrm{C}, 80 \%$ of the conidia trapped the prey during the first $24 \mathrm{~h}$, whereas at $8{ }^{\circ} \mathrm{C}$, no conidium was successful. The mycelium growth rate was the highest at $20^{\circ} \mathrm{C}(r=1.44)$ during the first $48 \mathrm{~h}$ but decreased during the following $24 \mathrm{~h}(r=0.98)$, suggesting the quickest use of resources. At a medium temperature of $15{ }^{\circ} \mathrm{C}$, the tendency was opposite, and the $r$ value was lower during the first $48 \mathrm{~h}$. At $8^{\circ} \mathrm{C}$, the growth rate was very low and remained at the same level even though numerous active rotifers were potentially available for the fungus. The temperature also influences the production of new conidia; on the 7th day, new conidia were observed in $96 \%$ of the wells at $20{ }^{\circ} \mathrm{C}$, but no new conidia were observed at $8^{\circ} \mathrm{C}$. These results show that the prey (rotifers)-predator (Lecophagus) dynamics in WWTPs is temperature-dependent, and a temperature of $8{ }^{\circ} \mathrm{C}$ is a
\end{abstract}

Electronic supplementary material The online version of this article (https://doi.org/10.1007/s00248-017-1060-5) contains supplementary material, which is available to authorized users.

Edyta Fiałkowska

edyta.fialkowska@uj.edu.pl

1 Institute of Environmental Sciences, Jagiellonian University, Gronostajowa 7, 30-387 Kraków, Poland strongly limiting factor for the fungus. Moderate temperatures ensure the most stable coexistence of the fungus and its prey, whereas the highest temperature can promote the prevalence of the predator.

Keywords Hyphomycetes · Conidia · Top-down control · Activated sludge $\cdot$ Wastewater treatment

\section{Introduction}

Predacious fungi are an ecological group comprising different phylla, such as Ascomycota, Zygomycota, Basidiomycota, and Zoopagales [1]. Thus far, approximately 200 species of predatory fungi have been described in the literature. Most predatory fungi are soil organisms that prey on nematodes as either endoparasites or nematode-trapping fungi [1-3]. Some fungi are also able to feed on tardigrades, amoebae, and rotifers. Approximately, 40 predacious fungi/fungi-like organisms occur in water habitats. Scarce reports mentioned the presence of predacious fungi in activated sludge [4-8]. While much is known regarding the biology and systematics of fungi feeding on nematodes [1-3,9], knowledge of biology and systematics of fungi preying on rotifers is rather limited, particularly regarding fungi that inhabit activated sludge [8].

Predacious fungi that feed on rotifers belong to the following two genera: Zoophagus and Lecophagus. The fungi that belong to the genus Zoophagus have been reported to feed mainly on loricated rotifers, whereas those belonging to the genus Lecophagus trap mainly bdelloid rotifers and tardigrades. Thus far, the only exception recently described is Lecophagus vermicola, which feed exclusively on nematodes [10]. All previously described species were isolated from wet habitats, such as moss, decaying plants on the banks of rivers and lakes, cyanobacterial mats, and animal feces [11-13], 
except for L. vermicola, which were isolated from bark fissures of Platanus and other trees [10]. In our recently published manuscript [8], we described the results of experiments conducted on a Zoophagus sp. isolated from activated sludge. The study showed that fungi can significantly reduce the number of Lecane and Bdelloidea individuals; however, Lecane inermis was the most affected [8]. The relationship between predacious fungi and rotifers in wastewater treatment plants (WWTPs) is of utmost importance because rotifers play a significant role in activated sludge. The loricated Lecane rotifers can reduce the growth of different filamentous bacteria species that are responsible for the highly disadvantageous phenomenon of activated sludge bulking and foaming [14-17], whereas bdelloid rotifers enhance floc formation and contribute to the reduction of excess sludge production $[18,19]$.

Temperature has been shown to greatly influence the growth and other life-history parameters of rotifers [20-23]. More detailed studies regarding the biology of Lecane rotifers originating from activated sludge have shown that these rotifers strongly depend on temperature. Studies investigating different clones of $L$. inermis have shown that generally, despite certain interclonal differences, their growth rate drastically decreases as the temperature decreases. A temperature of $8^{\circ} \mathrm{C}$, at which the value of the growth rate coefficient is nearly 0 , appears to be critical for this species. Nevertheless, certain clones of $L$. inermis have a positive growth rate, even at such a low temperature [24]. Other experiments aiming to select rotifers that have better adapted to low temperatures and are capable of limiting the growth of filamentous bacteria have led to the selection of $L$. tenuiseta clones, which can proliferate at temperatures as low as $8{ }^{\circ} \mathrm{C}[25]$. The abovementioned experiments were performed at a temperature range similar to that in WWTPs operating in temperate climate zones. As both species of Lecane are potential bulking and foaming control agents, knowledge regarding the conditions that contribute to their survival in activated sludge is necessary for optimizing their use as biological tools in real scale WWTPs.

Because it has been previously shown that a population of rotifers in activated sludge could be limited by predatory fungi and low temperatures, we designed a set of experiments to determine whether the growth of a predatory fungus isolated from activated sludge that belongs to the genus Lecophagus sp. depends on temperature. Furthermore, we aimed to characterize how temperature influences the susceptibility of rotifers Lecane sp. to the fungus.

\section{Materials and Methods}

In this experiment, we used clonal populations of the predacious fungus Lecophagus sp. and rotifers Lecane sp. that were isolated from wastewater treatment plants in Southern Poland.
The fungus was detected in a sample obtained from a small WWTP treating domestic waste. Some pieces of mycelium were then transferred to a Petri dish filled with Żywiec brand spring water, and the rotifers $L$. inermis were added as a food source. The dish was maintained in darkness at $20{ }^{\circ} \mathrm{C}$. When the fungus produced conidia, some of them were transferred individually to separate wells in 12-well tissue culture plates and maintained similarly. One of the obtained clones, coded as $\mathrm{Z1}$, was used in the experiment. We classified this fungus as Lecophagus according to a key provided by Dick [26], in which the main criterion distinguishing Lecophagus from Zoophagus is the septation of the mycelium. The fungus mycelium is approximately $6.5 \mu \mathrm{m}$ wide, branched and septate (Fig. 1). The length of the segments is 15 $21 \mu \mathrm{m}$. Conidiogenous cells lateral, bearing 2-5 conidia (Supplementary Material). The conidia septate, usually with 4-6 septa (Fig. 2). Most conidia are 4.9-6.6 $\mu \mathrm{m}$ wide and 95$125 \mu \mathrm{m}$ long, but solitary conidia of 82.0 or $140 \mu \mathrm{m}$ were also recorded. The adhesive pegs are broader at the base and clearly indented immediately below the rounded adhesive apex (Fig. 3). The pegs are 14-17 $\mu \mathrm{m}$ long. Because the biometric features do not entirely match any of the already described Lecophagus species, we decided to only use the genus name.

The rotifers L. inermis (clone Lt2.B5) were used as prey organisms. The clone Lt2.B5 was obtained from single individuals isolated from activated sludge samples. The samples were evenly distributed into the wells of tissue culture plates and maintained in darkness at $8{ }^{\circ} \mathrm{C}$. Throughout 2 years, the rotifers exhibiting the highest growth rate were transferred to new wells. Then, single individuals were transferred to new wells to obtain the clonal populations. The clone adapted to lower temperature obtained using a previously described selective procedure was then cultured at $8{ }^{\circ} \mathrm{C}$ in Żywiec brand spring water and fed NOVO (nutrition powder used for rotifer mass culture, patent EP2993978(A1)) [27]. Using clones adapted to lower temperatures ensured the rotifer survival at each temperature used in the experiments.

\section{The Experimental Setup}

Single conidia, which were approximately $100 \mu \mathrm{m}$ long, and $10 \mu \mathrm{l}$ of the medium were transferred to separate wells in three 24-well tissue plates using an automatic pipette. In total, $50 \mu \mathrm{l}$ of the rotifer culture were inoculated into each well; thus, approximately 100 active individuals were present in each well. Then, $1 \mathrm{ml}$ of Żywiec brand spring water was added. The plates were maintained in darkness at 8,15 , and $20^{\circ} \mathrm{C}$ each.

After $24 \mathrm{~h}$, we determined the number of conidia that managed to catch the rotifers, and the percentage of successful conidia was calculated at each temperature. After the following $24 \mathrm{~h}$, the conidia found on the bottom were measured 


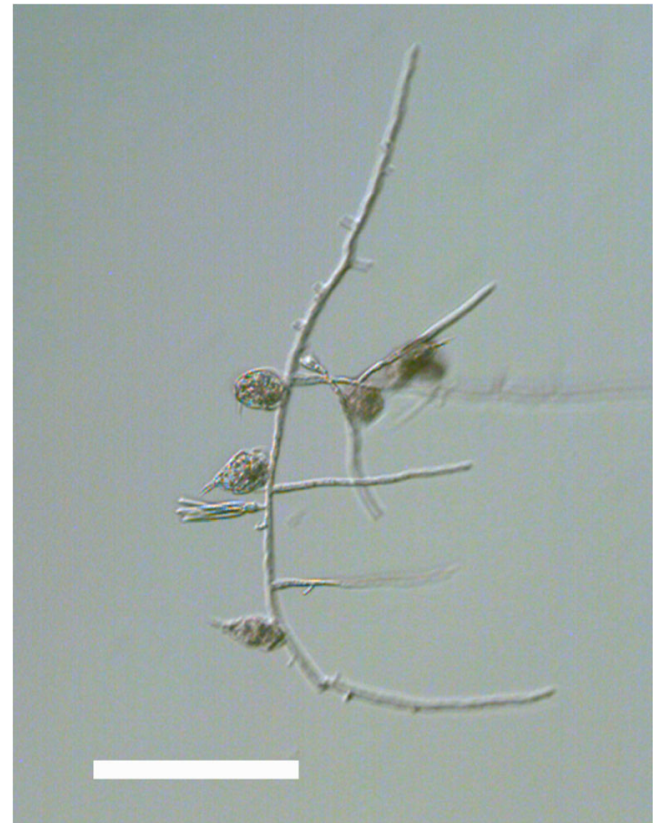

Fig. 1 Exemplary piece of Lecophagus sp. mycelium with trapped rotifers and conidia growing on a conidiophore cell. Scale bar indicates $200 \mu \mathrm{m}$

along with the mycelium that grew from the conidia. In certain cases, it was impossible to detect a conidium most likely because the conidia moved to the very edge of the well where they remained undetectable using an inverted microscope. The measurements were repeated after the following $24 \mathrm{~h}$. After the fourth day of the experiment ( $96 \mathrm{~h}$ after the start of the experiment), the pieces of mycelium, particularly those in the wells maintained at $20^{\circ} \mathrm{C}$, were already too long and started to grow upwards; thus, measuring these pieces became

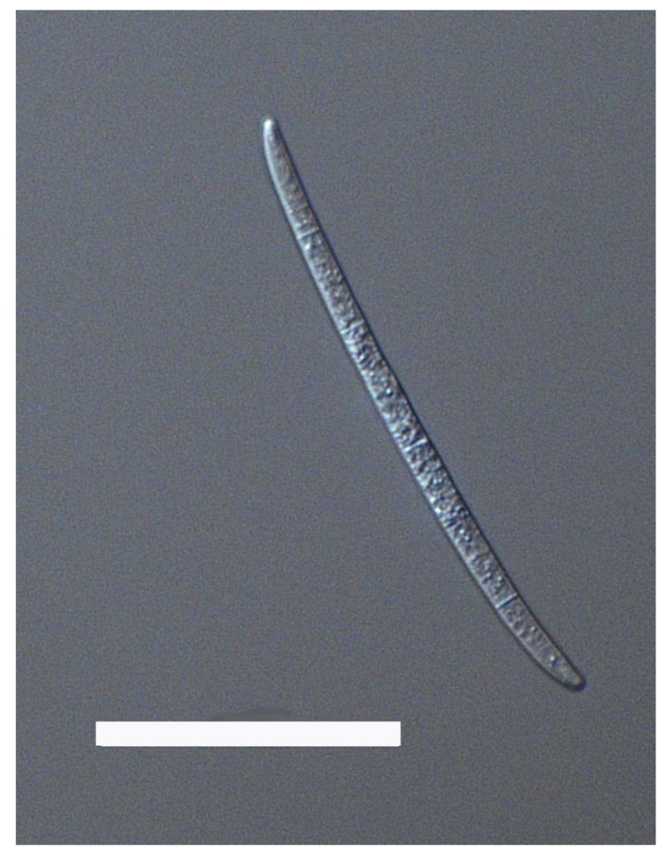

Fig. 2 Conidium with visible septa. Scale bar indicates $50 \mu \mathrm{m}$ impossible. Hence, further measurements were not obtained. Using the collected data, the mean growth rate was calculated during the first $48 \mathrm{~h}$ and the following $24 \mathrm{~h}$ according to the following formula, which was adapted for filamentous forms [28]:

$r=\left(\operatorname{Ln} N_{t}-\operatorname{Ln} N_{0}\right) \times \mathrm{t}^{-1}$, where $N_{\mathrm{t}}$ and $N_{0}$ refer to the final and initial lengths of the mycelium, and $t$ refers to time.

To determine whether there were significant differences in the mean growth rates of the fungus across the temperatures, we performed an ANOVA to analyze the first and the second measurements separately. The differences in the values of " $r$ " at each temperature were then analyzed using an Unequal $\mathrm{N}$ HSD test. The numbers of cases were not equal because we did not include the wells in which the fungi were not visible or those in which the conidium degenerated. We also determined whether there were significant differences in the mean growth rates between the first and second measurements at each temperature using a $t$ test.

To determine whether there were enough rotifers available for the fungus until the end of experiment, $96 \mathrm{~h}$ after the start of the experiment, the rotifers in each well were counted and categorized as active, inactive or caught by the fungus. Discriminating between active and inactive rotifers is important because according to our direct observations, in many cases, loricated rotifers can remain inactive for an extended time, but they are still alive and can regain movability.

On the same day, we also noticed that in certain wells, new conidia were produced by the fungus but only at a temperature of $20^{\circ} \mathrm{C}$. We checked the wells for fresh conidia again 3 days later.

We also wanted to determine the fate of the conidia that managed to trap a rotifer at the lowest temperature but did not grow during the experiment. Thus, the experimental wells were checked 11 and 30 days after the beginning of the experiment.

All observations were performed under an inverted Olympus microscope at a total magnification of $\times 200$.

The statistical analysis was performed using STATISTICA software v 12.0 [29].

\section{Results}

The observations performed $24 \mathrm{~h}$ after presenting rotifers to the conidia revealed significant differences in the percentage of conidia that caught rotifers at each temperature. The conidia maintained at $8{ }^{\circ} \mathrm{C}$ did not catch any rotifers, whereas almost $80 \%$ of those maintained at $20^{\circ} \mathrm{C}$ were successful. At $15^{\circ} \mathrm{C}$, the percentage of conidia that caught rotifers was intermediate (Fig. 4).

The ANOVA showed that there were significant differences across the temperatures in the mean growth rate of the fungus after the first $48 \mathrm{~h}\left(F_{2,47}=100.7, p<0.001\right)$ and after 
Fig. 3 Fragment of the fungus mycelium with clearly visible septa and adhesive pegs. Scale bar indicates $50 \mu \mathrm{m}$

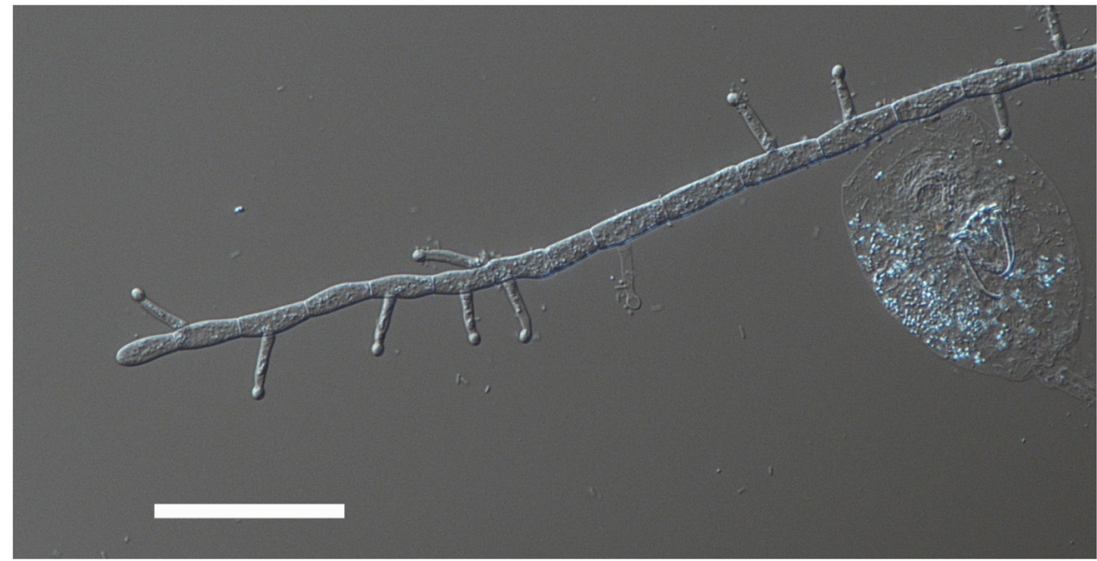

the following $24 \mathrm{~h}\left(F_{2,47}=52.49, p<0.001\right)$. At $8{ }^{\circ} \mathrm{C}$, the conidia did not grow during the experiment. The mean growth rate of the mycelium was nearly three times higher at $20^{\circ} \mathrm{C}$ than that at $15^{\circ} \mathrm{C}$ (Fig. 5). The Unequal N HSD test showed that the differences were significant at each of tested temperatures both after the first $48 \mathrm{~h}$ and the following $24 \mathrm{~h}$ (Fig. 5). Student's $t$ tests showed that the mean growth rate at $8{ }^{\circ} \mathrm{C}$ did not differ in time $\left(t_{14}=1.21, p=0.25\right)$, whereas at higher temperatures, the differences across consecutive days were significant $\left(t_{15}=5.11, p<0.001\right.$ at $15{ }^{\circ} \mathrm{C}$ and $t_{18}=2.77$, $p=0.01$ at $20^{\circ} \mathrm{C}$ ).

Figure 6 shows the mean fractions of active, inactive, and caught rotifers calculated at the end of the experiment. The results show that at each temperature, the fraction of active rotifers was the highest. At the lowest temperature, the fraction of caught rotifers was extremely low. At $15^{\circ} \mathrm{C}$, the fractions of active, inactive, and caught rotifers were similar to those observed at $8{ }^{\circ} \mathrm{C}$ with slightly higher fractions of inactive and caught rotifers. At $20^{\circ} \mathrm{C}$, the fractions of inactive and caught rotifers were higher than those at both lower temperatures.

Direct observations performed on the fourth day of the experiment revealed that at a temperature of $20^{\circ} \mathrm{C}$, new conidia were produced in $73 \%$ of the wells, whereas at the two

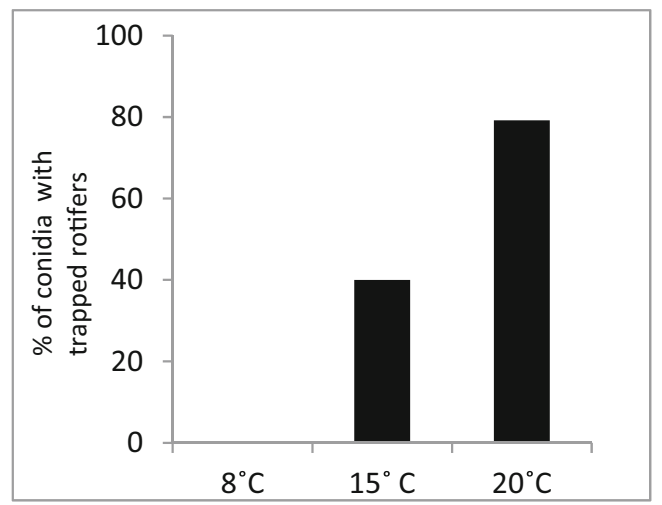

Fig. 4 Percentage of conidia with trapped rotifers $24 \mathrm{~h}$ after the start of the experiment lower temperatures, no new conidia appeared. Three days later, new conidia were observed in $96 \%$ of the wells at $20^{\circ} \mathrm{C}$ and $50 \%$ of the wells at $15^{\circ} \mathrm{C}$, but no freshly produced conidia were present at $8{ }^{\circ} \mathrm{C}$.

The observations of the fungus at the lowest temperature showed that on the 11th day of the experiment, the conidia were alive in 21 of the 24 experimental wells, and the mycelium started to grow and reached a length in a range of 271 to $744 \mu \mathrm{m}$ in 18 wells. In the three remaining wells, the conidia have not begun to elongate. On the 30th day of the

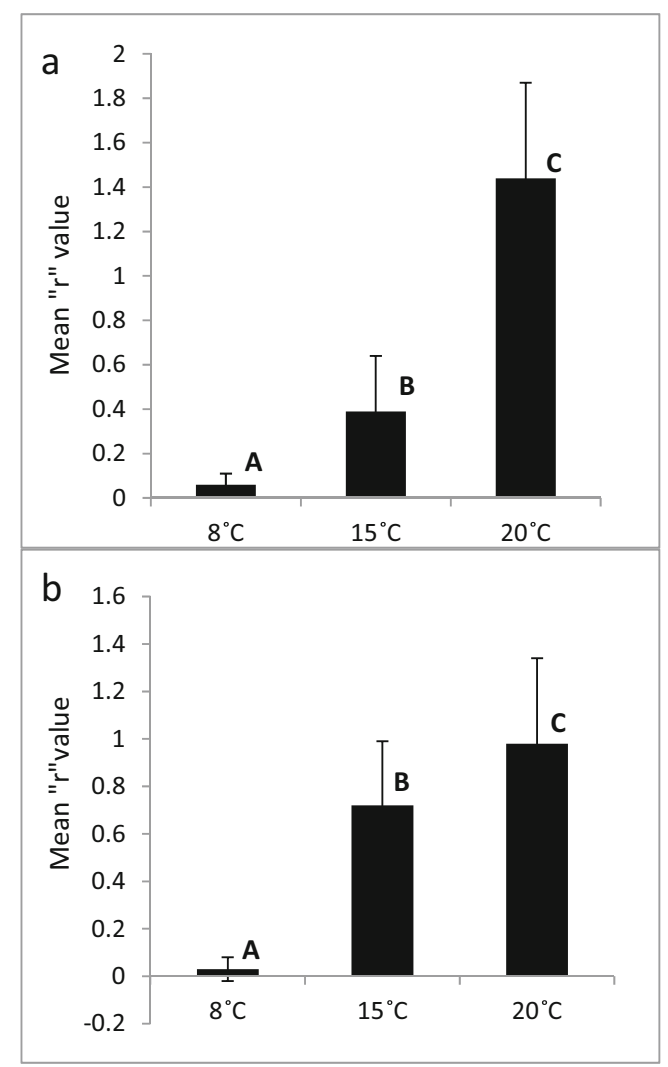

Fig. 5 Mean " $r$ " values after the first $48 \mathrm{~h}$ (a) and the following $24 \mathrm{~h}$ (b) at different temperatures. Capital letters indicate statistically significant differences. Bars indicate the standard deviations 


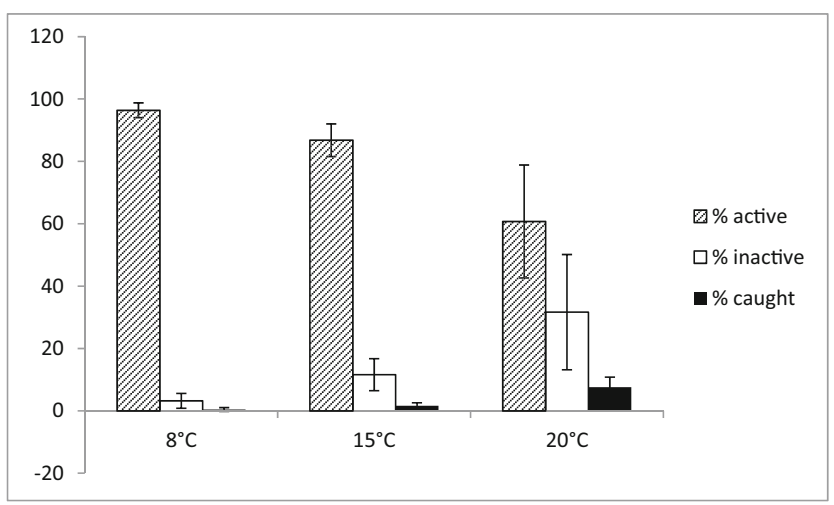

Fig. 6 Mean fraction of active, inactive, and caught rotifers $96 \mathrm{~h}$ after the start of the experiment at each temperature. Bars indicate the standard deviations

experiment, the conidia that failed to elongate previously were deteriorated, whereas in the remaining wells, the growing mycelium reached a length in the range of 355 to approximately $4100 \mu \mathrm{m}$.

\section{Discussion}

Predatory fungi are important, but until recently frequently overlooked, components of aquatic ecosystems. To date, not much is known regarding the influence of temperature on their life strategies even though temperature is considered an important factor influencing the significance of top-down and bottom-up effects in ecological communities [30,31]. Our study is the first investigation of the effect of temperature on predatory fungus growth and conidia germination. Evidence indicates that the optimal temperature for the growth of nematode-trapping fungi is between 20 and $25^{\circ} \mathrm{C}[9,32]$, but no data are available regarding the influence of temperature on the development of conidia and the growth rate of species that belong to the genera Lecophagus and Zoophagus and prey on rotifers. These fungi belong to aquatic hyphomycetes and are characterized by the production of conidia (asexual spores). Conidia constitute an important stage of the life cycle for dispersion and survival in adverse environmental conditions [10, 33].

The germination of conidia in most filamentous fungi has been shown to be regulated by low molecular-mass nutrients, such as inorganic salts, sugars, and amino acids [33, 34]. However, not much is known regarding the conditions that determine conidia germination in predacious fungi, particularly those belonging to the genus Lecophagus. Tzean and Barron [11] showed that in L. navicularis, conidia develop short adhesive appendages in the presence of rotifer prey. Conidia of $L$. vermicola produce adhesive knobs that are capable of capturing nematodes [10]. Other nematophagous fungi produce so-called conidial traps when germinating in habitats where the level of nutrients is low and competition for nutrients among microorganisms is strong [3].

The results presented here indicate that the activity and development of conidia are strictly temperature-dependent. Apparently, a temperature of $20^{\circ} \mathrm{C}$ is the most favorable. At this temperature, most conidia managed to trap a rotifer during the first $24 \mathrm{~h}$ of the experiment, whereas at the lowest temperature, no conidium was successful (Fig. 4). Although it has been reported that in the presence of rotifers, conidia of certain Lecophagus sp. germinate to produce adhesive pegs for trapping rotifers [35] and rotifers and tardigrades are attracted to adhesive pegs [13], no extensive studies investigating the relationship between conidia and their prey have been conducted. Our results clearly indicate that a temperature of $8{ }^{\circ} \mathrm{C}$ significantly slows the process of conidia germination. It might be argued that the rotifers may be less active at this temperature, but as even at the end of the experiment, the percentage of active rotifers at $8{ }^{\circ} \mathrm{C}$ remained high (Fig. 6), their reduced motility cannot be the only reason preventing the conidia from trapping the prey. Furthermore, if the conidia actually attract rotifers, their relatively limited motility should not prevent their capture, particularly when there were approximately 100 rotifers available for each conidium (Fig. 6). Apparently, higher temperatures enhance the trap formation and ability to trap the rotifers. It appears that because at $8{ }^{\circ} \mathrm{C}$, the conidia were barely able to catch rotifers and many conidia deteriorate over time, this temperature could limit the development and dispersion of this species in the environment. However, while the conidia did not germinate and trap any prey during the first $24 \mathrm{~h}$ at the lowest temperature, on the 30th day, the percentage of conidia that died was below $50 \%$. The remaining conidia managed to trap rotifers and eventually began to develop into quite long mycelium. This result shows that the fungus can grow at temperatures as low as $8{ }^{\circ} \mathrm{C}$. Because some rotifers can live and even proliferate at such a low temperature [25], the fungus can be expected to survive in adverse conditions during the winter season.

The comparison of the mycelium growth rate at different temperatures shows that the higher the temperature, the higher the growth rate, whereas the lowest temperature considerably limits the growth of Lecophagus (Fig. 5). The growth rate at the highest and medium temperatures changed across the consecutive days of the experiment. At $20^{\circ} \mathrm{C}$, the fungus growth was faster during the first day and slowed on the following day. The opposite tendency was observed at the medium temperature. At the lowest temperature, the mycelium began to grow, but the process was very slow and practically did not change across the days. The temperature of $8{ }^{\circ} \mathrm{C}$ was also shown to be a limiting factor for the growth of the L. inermis rotifers. Apparently, the temperature-dependent development of predatory fungi is ecologically coupled to the life-history of its prey. The decreasing growth rate at $20{ }^{\circ} \mathrm{C}$ might have been caused by the decreasing percentage of active 
rotifers. Because the fungus grows quickly and its growth is strongly dependent on the availability of prey organisms, the fungus can quickly overexploit its resources. At medium temperatures, the whole process is slower, allowing the high growth rate to persist. Another factor might have also influenced the growth rate of the fungus at the highest temperature. On the day we quantified the percentage of active rotifers, we also observed that in 16 of the 24 wells at $20^{\circ} \mathrm{C}$, the hyphae began to produce new conidia, whereas no new conidia were observed at 15 or $8{ }^{\circ} \mathrm{C}$. The production of spores in aquatic hyphomycetes was shown to depend on the temperature and nutrients, among other factors. The increase in the temperature and nutrient concentrations results in intensified growth and sporulation $[1,36]$. Again, the data did not include predatory fungi with possibly different physiological reactions. In our experiment, no additional nutrients were added, but because predatory fungi depend mainly on trapped prey, increases in the number of trapped rotifers should result in a higher conidia production. Thus, the influence of temperature on conidia production might be indirect.

In the case of aquatic hyphomycetes, fungi have been shown to allocate up to $80 \%$ of their production to conidia [37]. If similar processes occur in predatory fungi, these processes could explain why the growth of the mycelium at the highest temperature rapidly slowed. However, Smith [38] suggested that the growth of the mycelium and sporulation in filamentous fungi are cellular processes that compete for limited metabolic factors rather than being mutually exclusive phenomena. If vegetative growth and sporulation do not occur simultaneously, the limited vegetative growth may be caused by nutrient shortages [38]. Therefore, our results suggest that at the highest temperature, the fungus used most of the nutrients during the first $48 \mathrm{~h}$.

Our experiment illustrates the possible predator-prey dynamics at average temperature ranges in a moderate climate. Apparently, the most stable coexistence of predatory fungus and its rotifer prey is possible at a temperature of approximately $15^{\circ} \mathrm{C}$, whereas at a temperature as low as $8{ }^{\circ} \mathrm{C}$, the fungus development is limited mainly by its temperature-dependent internal growth rate. At the highest temperature of $20^{\circ} \mathrm{C}$, the rotifer population is strongly limited by the predatory fungus, and then, the fungus growth is limited by the shortage of active rotifers. This hypothesis is consistent with conclusions drawn by Hoekman [30], who stated that a higher temperature may increase the strength of top-down effects. Therefore, the understanding of how communities respond to changes in temperature is a challenge in community ecology. These phenomena are particularly pronounced in the biocenoses of wastewater treatment plants. The biological processes present in WWTPs provide perfect conditions for the fast coevolution of activated sludge inhabitants due to nearly unlimited nutrient resources. Therefore, studies investigating the communities evolving in these systems could help predict how the predator-prey dynamics evolve in changing environments.

Acknowledgments This study was supported by the National Center for Research and Development Grant GEKON1/O3/214361/8/2014 and Jagiellonian University Funds DS/WBiNoS/INoS/757.

Open Access This article is distributed under the terms of the Creative Commons Attribution 4.0 International License (http:// creativecommons.org/licenses/by/4.0/), which permits unrestricted use, distribution, and reproduction in any medium, provided you give appropriate credit to the original author(s) and the source, provide a link to the Creative Commons license, and indicate if changes were made.

\section{References}

1. Jones EG, Hyde KD, Pang KL (eds) (2014) Freshwater fungi: and fungal-like organisms. Walter de Gruyter GmbH \& Co KG, Berlin/ Boston

2. Nordbring-Hertz B, Jansson, H B, Tunlid A (2006) Nematophagous fungi. Encyclopedia of Life Sciences, John Wiley \& Sons, www.els.net, https://doi.org/10.1038/npg.els.0004293

3. Liu X, Xiang M, Che Y (2009) The living strategy of nematophagous fungi. Mycoscience 50(1):20-25

4. Cooke WB, Ludzack FJ (1958) Predacious fungus behavior in activated sludge systems. Sewage Ind Waste 30(12):1490-1495

5. Pipes WO, Jenkins D (1965) Zoophagus in activated sludge-a second observation. Air Wat Poll 9:495-500

6. Sladká A, Ottová V (1973) Filamentous organisms in activated sludge. Hydrob 43(3):285-299

7. Gray NF (1984) The effect of fungal parasitism and predation on the population dynamics of nematodes in the activated sludge process. Ann Appl Biol 104(1):143-149

8. Pajdak-Stós A, Ważny R, Fiałkowska E (2016) Can a predatory fungus (Zoophagus sp.) endanger the rotifer populations in activated sludge? Fungal Ecol 23:75-78

9. Zhang KQ, Hyde KD (eds) (2014) Nematode-trapping fungi (Vol. 23). Springer, Dordrecht

10. Magyar D, Merényi Z, Bratek Z, Baral HO, Marson G (2016) Lecophagus vermicola sp. nov., a nematophagous hyphomycete with an unusual hunting strategy. Mycol Prog 15(10-11):1137-1144

11. Tzean SS, Barron GL (1983) A new predatory hyphomycete capturing bdelloid rotifers in soil. Can J Bot 61(5):1345-1348

12. Glockling SL (1997) Zoophagus cornus: a new species from Japan. Mycol Res 101(10):1179-1182

13. McInnes SJ (2003) A predatory fungus (Hyphomycetes: Lecophagus) attacking Rotifera and Tardigrada in maritime Antarctic lakes. Pol Biol 26(2):79-8214

14. Fiałkowska E, Pajdak-Stós A (2008) The role of Lecane rotifers in activated sludge bulking control. Water Res 42(10):2483-2490

15. Kocerba-Soroka W, Fiałkowska E, Pajdak-Stós A, Klimek B, Kowalska E, Drzewicki A, Salvado H, Fyda J (2013) The use of rotifers for limiting filamentous bacteria type $021 \mathrm{~N}$, a bacteria causing activated sludge bulking. Water Sci Technol 67(7):1557-1563

16. Drzewicki A, Kowalska E, Pajdak-Stós A, Fiałkowska E, KocerbaSoroka W, Sobczyk Ł, Fyda J (2015) Experimental attempt at using Lecane inermis rotifers to control filamentous bacteria Eikelboom type 0092 in activated sludge. Water Environ Res 87(3):205-210

17. Pajdak-Stós A, Kocerba-Soroka W, Fyda J, Sobczyk M, Fiałkowska E (2017a) Foam-forming bacteria in activated sludge effectively reduced by rotifers in laboratory-and real-scale wastewater treatment plant experiments. Environ Sci Pollut Res 24(14): 13004-13011 
18. Lee NM, Welander T (1996) Reducing sludge production in aerobic wastewater treatment through manipulation of the ecosystem. Water Res 30(8):1781-1790

19. Lapinski J, Tunnacliffe A (2003) Reduction of suspended biomass in municipal wastewater using bdelloid rotifers. Water Res 37(9): 2027-2034

20. Galkovskaja GA (1987) Planktonic rotifers and temperature. Hydrob 147(1):307-317

21. Pérez-Legaspi IA, Rico-Martínez R (1998) Effect of temperature and food concentration in two species of littoral rotifers. Hydrob 387/388:341-348

22. Stelzer CP (2002) Phenotypic plasticity of body size at different temperatures in a planktonic rotifer: mechanisms and adaptive significance. Funct Ecol 16(6):835-841

23. Kiełbasa A, Walczyńska A, Fiałkowska E, Pajdak-Stós A, Kozłowski J (2014) Seasonal changes in the body size of two rotifer species living in activated sludge follow the temperaturesize rule. Ecol Evol 4(24):4678-4689

24. Fiałkowska E, Kocerba W, Pajdak-Stós A, Klimek B, Fyda J (2011) Clonal variation in reproductive response to temperature by a potential bulking control agent, Lecane inermis (Rotifera). Water Sci Technol 64(2):403-408

25. Fiałkowska E, Pajdak-Stós A, Fyda J, Kocerba-Soroka W, Sobczyk M (2016) Lecane tenuiseta (Rotifera, Monogononta) as the best biological tool candidate selected for preventing activated sludge bulking in a cold season. Desalin Water Treat 57(59):28592-28599

26. Dick MW (1990) The systematic position of Zoophagus insidians. Mycol Res 94(3):347-354

27. Pajdak-Stós A, Fiałkowska E, Fyda J, Kocerba-Soroka W, Sobczyk M (2017b) A method of mass culture of Lecane rotifers European Patent EP 14731401.7
28. James CM, Dias P (1984) Mass culture and production of the rotifer Brachionus plicatilis using Baker's yeast and marine yeast. Ann Res Rep Kuw Inst Sci Res 49-51

29. StatSoft In (2011) STATISTICA (data analysis software system), version 10. www.statsoft.com

30. Hoekman D (2010) Turning up the heat: temperature influences the relative importance of top-down and bottom-up effects. Ecology 91(10):2819-2825

31. Velthuis M, Senerpont Domis LN, Frenken T, Stephan S, Kazanjian G, Aben R, et al. (2017) Warming advances top down control and reduces producer biomass in a freshwater plankton community. Ecosph 8(1):1-16

32. Fernandez AS, Larsen M, Wolstrup J, Grønvold J, Nansen P, Bjørn $\mathrm{H}$ (1999) Growth rate and trapping efficacy of nematode-trapping fungi under constant and fluctuating temperatures. Parasitol Res 85(8):661-668

33. Osherov N, May GS (2001) The molecular mechanisms of conidial germination. FEMS Microbiol. Lett. 199(2):153-160

34. Carlile MJ, Watkinson SC (1994) The fungi. Academic Press, London

35. Barron GL, Morikawa C, Saikawa M (1990) New Cephaliophora species capturing rotifers and tardigrades. Can. J. Bot. 68(3):685690

36. Gulis V, Suberkropp K (2004) Effects of whole-stream nutrient enrichment on the concentration and abundance of aquatic hyphomycete conidia in transport. Mycol 96(1):57-65

37. Suberkropp K (1995) The influence of nutrients on fungal growth, productivity, and sporulation during leaf breakdown in streams. Can. J. Bot. 73(S1):1361-1369

38. Smith JE (1978) Asexual sporulation in filamentous fungi. In: Smith JE, Berry DR (eds) The filamentous fungi vol. 3. Arnold, London, p. 214-239 